\title{
La producción y utilización de gránulos de arcilla expandida en la literatura del ramo
}

HEINZ SCHMIDT

Die Ziegelindustrie, n॰ 21/22, noviembre 1970, págs. 463-471

\section{Historia de LA PRODUCCION DE ARCILla EXPANSIVA}

Los primeros intentos de producción de materiales de construcción ligeros, mediante poros en ladrillos cerámicos con ayuda de materias combustibles en forma finísima, se remontan a las épocas del imperio sumerio-babilónico, aproximadamente en el año 2.500 a. C.

En Alemania se patentó por primera vez un procedimiento de obtención de "cuerpos arcillosos porosos por evaporación rápida de agua" el 27 de abril de 1880 Braunschweiger G. Kükenthal bajo el n. 12.878 [108]. Ya el año 1912 St. Hayde de EE.UU. realizó los primeros ensayos para el aprovechamiento del fenómeno expansivo de esquistos arcillosos, y en 1913 se le concedió también una patente [54]. Los primeros gránulos de arcilla expandida elaborables de acuerdo con la técnica de la construcción se produjeron, según la patente USA n. ${ }^{\circ} 1.255 .878$ de fecha 12 de febrero de 1918, por Stephen John Hayde. Una patente, concedida el 2 de septiembre de 1919 a Oskar Ohlsen, no pudo utilizarse económicamente por discusión de patentes [108].

El granulado de arcilla expansiva aparecido en el comercio norteamericano bajo el nombre de HAYDITE se empleó al principio como árido ligero para la construcción de buques de hormigón, como consecuencia de la falta de acero una vez ya acabada la $1 .^{a}$ guerra mundial. Después de diversas construcciones navales eficaces, pronto se unió en su consumo la industria americana de la construcción, con lo que casi se triplicó la producción desde el fin de la $1 .^{\text {a }}$ guerra mundial hasta 1945. Cuando termina la $2 .^{\text {a }}$ guerra mundial experimenta un notable aumento el empleo de productos de arcilla expandida en las construcciones elevadas y subterráneas, de tal forma que la producción en EE.UU. de arcilla expandida en el año 1955 fue de 1,7 millones de $\mathrm{m}^{3}$ y en 1958 alcanzó más de los 3 millones de $\mathrm{m}^{3}$ [108].

Según Steinicke [108], puede considerarse a Dinamarca como el país del desarrollo de la arcilla expandida en Europa, pues ya antes y durante la $2 .^{a}$ guerra mundial se levantaron muchas viviendas a base de este material. En Rösnes, cerca de Kalundborg, se erigió la primera factoría de arcilla expandida, la cual producía granulado de arcilla expansiva bajo el nombre de LECA en un horno rotatorio.

Entre los países de la Europa oriental donde primero tuvo lugar la producción de arcilla expandida fue en Checoslovaquía y después, a mayor escala, en la URSS, donde la arcilla expandida producida se vende bajo el nombre comercial de KERAMSIT. 
Prescindiendo de pequeños intentos, la primera producción de arcilla expandida económicamente rentable producida en Alemania tuvo lugar en los años 1935 a 1939 en Sommerfeld/Niederlausitz y en Rüdersdorf/Berlín, según una patente de Philipp Holzmann AG. Con la misma patente se produjeron también granulados de arcilla expandida en Nienburg/Saale durante la 2. ${ }^{\text {a }}$ guerra mundial y se utilizó exclusivamente para la construcción de buques de hormigón ligero. La sugerencia parece ser que procede de Noruega, en donde ya se había empleado material Hovint para la construcción de buques mercantes medianos a fin de economizar acero. Después de la 2. ${ }^{a}$ guerra mundial surgió la primera factoría de arcilla expandida en Itzehoe/Mittelholstein, que a partir de febrero de 1956 produjo este material con arreglo al procedimiento danés LECA [108].

La primera bibliografía digna de mención sobre la producción de áridos ligeros de arcillas, esquistos arcillosos y otros materiales, apareció en el año 1948 como informe de investigación del Ministerio del Interior Americano [1]. Dos años más tarde se informó en el "British Clayworker" sobre el ensayo de arcillas con respecto a su idoneidad como áridos para construcciones ligeras [2]. En la misma revista se describe en 1951 un procedimiento desarrollado en el North Carolina State College para la producción de grandes elementos cerámicos ligeros a base de una mezcla de arcilla y áridos ligeros [5]. Asimismo, en el "British Clayworker" [4] y en el "Journal of the American Ceramic Society" [3], Ch. M. Riley informa resumidamente sobre el estado actual de la explicación de las causas de la expansión de las arcillas. El mismo año se publica en una revista canadiense un artículo sobre "Arcillas expansivas y arcillas esquistosas como áridos ligeros" [6]. En el cuaderno n. ${ }^{\circ}$ 12/1952 de la revista "Osterreichischen Zieglerzeitung", K. Bergmann trata [9] de diversos requisitos que hay que exigir a los materiales de construcción.

Entre otras cosas, se menciona también la expansión de las arcillas por desarrollo de gases. Sobre este mismo asunto apareció el año 1952 una publicación de Meyer en la "Revista de la industria ladrillera" sobre la "Producción industrial de áridos para la fabricación de hormigón ligero de pasta de ladrillos o materias primas similares" [10]. En los años 1952-1956 se publicaron, en rápida sucesión, diversos artículos americanos, británicos, canadienses y uno danés sobre la producción de arcilla expandida, el desarrollo de bloques cerámicos ligeros y la utilización de LECA para el aislamiento térmico [7], [8] y [11 a 28].

En el cuaderno n. 2 (1956) de la revista alemana "Zement-Kalk-Gips" Th. Kristen informa sobre "Ensayos con arcilla expandida obtenida de arcilla alemana", que se coció a modo de ensayo en el horno rotativo danés [29]. Siguen el mismo año, en la revista "Silikattechnik", un artículo de L. Schàtzer [30] con el título de "Aridos cerámicos para hormigón ligero" y un trabajo sobre "Cerámica esponjosa" de W. Kalb y E. Wilhelm [31]. Dunham [32], Catschpole [33] y Pfeiffenberger [34] se ocupan en el año 1957, en diversas revistas de habla inglesa, de la producción de áridos ligeros de arcilla de acuerdo con el procedimiento de sinterización en parrilla. Igualmente, en 1957, Steinicke trata por primera vez, en una revista alemana, del nuevo material de construcción "Arcilla expandida LECA" [35]. Además de cuatro publicaciones americanas [36 a 39] en el año 1958, W. Stanzak describe, en "Silikattechnik" n. 4 (1958), la "Producción de KERAMSIT en Checoslovaquia" [40] y F. Kaempfe, en la revista "Zement-Kalk-Gips", los ensayos con arcillas de aluvión australianas [41]. Un informe digno de mención apareció el mismo año en la revista soviética "Steklo y Keramika", de J. N. Cernjak, sobre los fundamentos físicos del proceso de expansión de arcillas de fácil fusión [42].

En 1959 y 1960 se publicaron en la revista americana "Brick \& Clay Record" varios" artículos [43 a 47], [51] y [56], que se ocupaban preferentemente de la producción de ladri- 
llos ligeros aglomerados con arcilla o bien de bloques ligeros de arcilla. H. Fastabend y J. L. Ruyter informan, en "Tonindustrie-Zeitung" (1959), de "Investigaciones sobre las cualidades de hinchamiento de arcillas de marismas" [49]. En "Silikattechnik" cuaderno n. 3 (1959), J. N. Tschernjak explica más detalladamente los fundamentos físicos del proceso de expansión [50]. Al año siguiente L. H. Blyumen se ocupa, en la revista "Steklo y Keramika", de la naturaleza físico-química de la expansión de arcillas [57] y V. F. Pavlov se explaya, en otro cuaderno de esta revista, sobre la "influencia del cambio de la viscosidad de arcillas de fácil fusión en el intervalo de $800^{\circ}-1.200^{\circ} \mathrm{C}$ al sinterizado y la expansión" [58]. Las demás publicaciones en los años 1960-1963 de las diversas revistas del país y extranjeras tratan principalmente de la puesta en marcha de nuevas factorías de arcilla expandida [62], [64], [67], [72] y [78] y de la fabricación de bloques ligeros de arcilla [65], [66], [68], [69], [73], [74], [75] y [82]. El artículo más aclaratorio en lo que se refiere al ensayo en el laboratorio de arcillas con respecto a su capacidad de expansión, así como a la composición de los gases expansivos, fue publicado en la revista "Die Ziegelindustrie" n. 24 (1963) por W. Schellmann y H. Fastabend bajo el título "Investigaciones sobre el proceso de expansión en arcillas" [89]. Ya al año siguiente el austríaco G. Bertoldi hizo un resumen sobre las condiciones físicas, químicas y mineralógicas previas para la fabricación de productos de arcilla expandida, en la "Euro-Ceramic" [96]. El mismo año apareció, en "Beton Verlag" en Düsseldorf, un libro de K. Walz y G. Wischers sobre el "Estado del desarrollo en los EE.UU, de áridos de arcilla expandida en horno rotatorio" [97]. A este sigue un año después, en la editorial "Bauverlag" de Wiesbaden, el libro de K. H. Steinicke sobre "Hormigón pretensado ligero y hormigón ligero de arcilla expandida y arcilla esquistosa expandida" [108].

Otras publicaciones aparecieron después en forma de conferencias con motivo de las " 3 jornadas ladrilleras 1966" en Essen, que en parte se reproducen en el cuaderno 11/12 de la revista "Die Ziegelindustrie". Se trata aquí de declaraciones de E. A. Siemssen (USA) sobre el "Procedimiento SELAS" [118] y K. Grosskopf sobre la producción de arcilla expandida con arreglo al "Método de. vibración" y el "Método de circulación-corriente" [117], mientras que K. Bergmann en su conferencia "Experiencias en la producción y utilización de arcilla expandida" expone el "Procedimiento LECA" [116]. El mismo cuaderno contenía una traducción del ruso de J. Böhm, en la que se explica una factoría de Keramsit con un horno de doble tambor [119]. G. Schellbach informó en su conferencia "Novedades de la construcción con piezas terminadas de ladrillos y arcilla expandida", entre otras cosas, sobre pruebas de la calidad (idoneidad) de estas arcillas en el Instituto de investigaciones de ladrillos en Essen [121].

En "Die Ziegelindustrie" n.o 14 (1967) N. Awerbuch trata de un nuevo procedimiento patentado en Francia para la producción de gránulos de arcilla esponjosa [125]. El "Anuario de la técnica ladrillera 1968" (Bauverlag, Wiesbaden), publica un informe resumido de A. Steindl sobre los áridos cerámicos expandidos en las construcciones actuales [130], y la firma MIAG, Braunschweig, en el mismo anuario y bajo el título "Instalación para cocción de arcilla expandida" [131] expone un precalentador de parrilla y uno de cuba para hornos rotatorios. El mismo año W. Schellmann informa sobre sus investigaciones en relación con "La capacidad expansiva de arcillas y sus causas" [133] en "Sprechsaal" n. ${ }^{\circ}$ 17/18 (1968), siguiendo en el n." 22 de esta revista la "Aportación para la expansión de arcillas y productos de chamota de la industria refractaria, sobre todo de los ladrillos expandidos para crisoles" de G. Routschka y Ch. Buttgereit [134]. En la revista "Silikattechnik" n.o 11 (1969) trata después H. Hoffmann de "La capacidad expansiva de la pizarra para cubiertas de Unterloquitzer" [141]. Diversos caminos para la "Trabazón cerámica de 
granulados de arcilla expansiva" se tratan y muestran en la revista "Die Ziegelindustrie" en el n. ${ }^{\circ} 11 / 12$ (1969) por H. J. Krause [143] y en el n. 20 (1969) por la firma F. Kettenbauer [144]. En el "Anuario de la técnica ladrillera 1970" se describe por último, en su parte "Novedades técnicas", una "Instalación de arcilla expandida de Krupp", según la cual un horno con precalentador vertical sólo requiere un consumo de calor de 750-800 kcal por kg de arcilla expandida [150].

\section{CONDICIONES PRevias sobre las primeras materias Y el PRoceso DE EXPANSION}

Como quiera que la composición químico-mineralógica de la materia prima puede influir notablemente en la calidad del producto expandido cocido, una arcilla que ha de emplearse en la producción de este producto debe de tener las siguientes características:

1. La máxima plasticidad posible [96] y gran proporción de grano fino [89], [98] y [130].

2. Las combinaciones orgánicas pueden estar representadas en gran medida ya que fomentan el proceso expansivo [96], [98], [108], [118] y [130].

3. El contenido de cal no debe exceder del $5 \%$ [60], [96], [108] y [130].

4. La proporción de cuarzo, hornablenda, etc. debe ser, en lo posible, menor de $40 \%$ [74], [96] y [108].

5. El contenido de minerales arcillosos de los grupos de la illita o la mica debe ser elevado [44], [74], [96] y [151]. Asimismo es provechosa la montmorillonita [97] y [151]. El contenido de caolinita debe ser escaso [96] y [151].

6. El óxido de hierro (por lo menos 3-6\%) y los álcalis deben estar suficientemente representados [31], [96], [97], [108], [116], [135] y [151].

7. Escaso contenido de ácidos, a ser posible valor $\mathrm{pH}>6$ [89] y [108].

8. Las sustancias que contienen azufre pueden estar representadas ampliamente. Pero, sin embargo, no son deseables como residuo en el granulado de arcilla expandida [96] y [97].

9. Los puntos de sinterización y de fusión deben estar próximos entre sí y por debajo de $1.200^{\circ} \mathrm{C}$, a fin de mantener bajo el costo de la cocción [89], [96] y [108].

10. El desprendimiento de gases y el reblandecimiento de la masa durante la cocción deben encontrarse en una gama de temperaturas estrecha [89], [96] y [98].

11. Es adecuado un intervalo de expansión de $50^{\circ}-100^{\circ} \mathrm{C}$ [135].

Para todas las arcillas esquistosas y esquistos arcillosos que se expanden en estado machacado no tiene validez el requisito de grano fino y elevada plasticidad, como es natural.

La composición química de las arcillas expandibles y no expansivas se confrontaron por Ch. M. Riley en un diagrama de tres sustancias [3] y [4]. La gama útil para arcilla expandida se limita por una línea a trazos (fig. 1).

Por consiguiente, es de esperar un comportamiento favorable en la fusión de arcilla expandida si la proporción es de:

$\mathrm{SiO}_{2}$ entre 55 y $78 \%$ en peso,

$\mathrm{Al}_{2} \mathrm{O}_{3}$ entre 12 y $25 \%$ en peso y la suma de fundentes se halla comprendida entre 8 y $25 \%$ en peso. 
W. Kalb y E. Wilhelm señalan los intervalos de composición química de arcillas expandibles, arcillas esquistosas y esquistos arcillosos [31]:

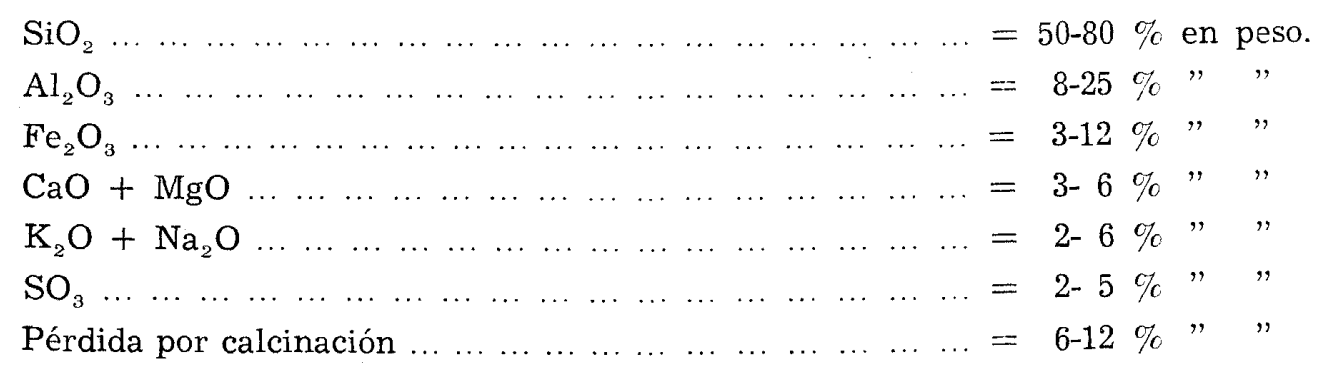

Las 5 arcillas analizadas en 1963 [89] por W. Schellmann y H. Fastabend, según otra publicación de W. Schellmann [133] se encuentran en los intervalos para arcilla expansiva delimitados por Riley, por lo que de esto no deben sacarse conclusiones cuantitativas.

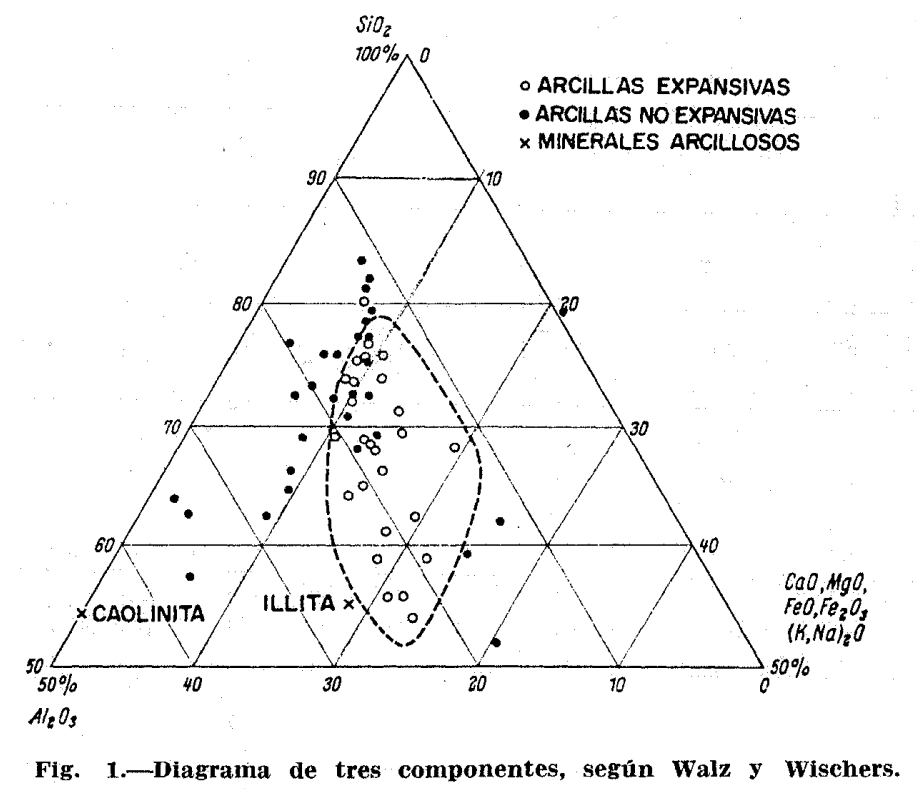

Hay arcillas que, por naturaleza, no poseen ninguna condición previa para la expansión, pero pueden ser influidas de tal modo por los llamados auxiliares de expansión o reguladores, que pueden llegar a producir una buena arcilla expansiva. Se trata de las siguientes sustancias:

- $\mathrm{SiO}_{2}$ ó $\mathrm{Al}_{2} \mathrm{O}_{3}[3]$.

- Nefelinsienita [97].

- Caliza o dolomita [30], [48] y [97].

- Oxidos e hidróxidos de hierro [31], [96], [97] y [124].

- Pirita, marcasita y sulfatos [97] y [124].

- Harina [118].

- Betún [96].

- Aceite pesado con elevado residuo de C [30], [97].

- Aceite Diesel [89]. 
- Carbón [57], [97], [98] y [118].

- Lejía sulfítica de desecho [30], [96] y [97].

- Coques [26].

- Vidrio de ventanas [57].

- Serrín [57].

Según Tschernjak [50], los procesos expansivos pueden considerarse, en el sentido físico, como suma de un número infinito de aumentos de volumen de poros individuales cerrados bajo el influjo de la presión de los gases contenidos en ellos. Por lo que, el aumento de volumen depende de la viscosidad del sistema, de la presión de los gases en cada caso y de la duración de la acción de la temperatura. El óptimo de viscosidad en arcillas se halla entre $5 \times 10^{8}$ y $5 \times 10^{7}$ Poises al presionar varios $\mathrm{kp} / \mathrm{cm}^{2}$ [50]. Calentándose rápidamente los gránulos hasta unos $1.100^{\circ} \mathrm{C}$, además de vapor de agua de humedad residual, se forma también oxígeno, vapor de agua de constitución y condensación de $\mathrm{OH}$, gases de la descomposición de materia orgánica, dióxido de azufre y anhídrido carbónico procedente de carbonatos, mientras que al mismo tiempo se cierran los poros de la superficie. Como quiera que los gases se expanden al aumentar la temperatura, se forma un producto expandido con una estructura interna de celdas más o menos finas [61], [89] y [96].

Como determinaron Hill y Crook, la reacción formadora de gases con la que más a menudo se tropezó fue la reducción de hierro III a hierro II [59]. Según las investigaciones de W. Schellmann y H. Fastabend, que analizaron los gases inmediatamente después de la expansión, la mayor parte de ellos procede de la desintegración térmica de la sustancia orgánica y se trata, preferentemente, de $\mathrm{Co}, \mathrm{N}_{2}$ y $\mathrm{H}_{2}$ [70], [71] y [88].

Por un productor de arcilla expansiva se entiende generalmente como tal, un producto cerámico poroso expandido a más de $1.000^{\circ} \mathrm{C}$ procedente de arcilla, limo, arcilla esquistosa o esquisto arcilloso con recubrimiento exterior sinterizado. Un producto expandido de forma redonda o con aristas se denomina granulado de arcilla expandida y una de configuración en forma de astillas (fragmentos) con ángulos y aristas agudos es mejor llamarlo ripio de arcilla expansiva. Con arcillas directamente expandidas en moldes se habla de ladrillos de arcilla expandida [96].

Los productos de arcilla expandida han de ser en general ligeros y tener un peso aparente de 0,3 a 0,7 , en tanto que el de ladrillos se mueve preferentemente de 1,7 a 1,9. Los productos con bajo peso específico se utilizan para aislamiento térmico y los de peso específico mayor y, por lo tanto, mayor resistencia, como árido para hormigón ligero y hormigón ligero pretensado [89] y [96].

\section{METODOS DE PRODUCCION Y EXPANSION}

Debido a que los métodos de preparación de las arcillas expandidas son, en principio, los mismos que en una fábrica de ladrillos, pueden utilizarse en general las máquinas de la industria ladrillera [96] y [108]. Es decir, las arcillas se obtienen en el terreno con ayuda de una excavadora de cangilones o de cuchara o con una retroexcavadora o similares y se lleva a la instalación preparadora semihúmeda o seca. Según la materia prima de partida, en la preparación semihúmeda se recorren distintas etapas como son molino de rulos, mezcladora de doble eje, laminador fino, etc., mientras que en la preparación en 
seco, la mayoría de las veces, el material granulado se criba en determinados tamaños y sin más tratamiento previo llega al horno [30], [67], [81], [97], [108], [130], [136], [145] y [148]. Los activadores de la expansión que eventualmente se necesiten u otros reguladores se añaden al iniciarse la preparación semihúmeda, a fin de conseguir una distribución uniforme [130].

La configuración se realiza, después de la preparación semihúmeda, bien en la de hilado corriente (en parte con instalación de vacío), en la que se estiran las cintas de arcilla y con un alambre separador se cortan en trozos de 10 a $12 \mathrm{~mm}$ de largas [31], o bien la arcilla se presiona a través de una placa perforada y las "salchichas" que salen se fraccionan con un cortador rotativo de alambre en trozos de 10 a $20 \mathrm{~mm}$ de longitud [40] y [83]. Si puede prescindirse de una prensa por tornillo sin fin, las "salchichas" del alimentador circular de criba [81] y las del laminador perforado [93], o bien los flanes del laminador fino, se utilizan como producto de partida para la obtención de gránulos [67], [96] y [108]. La granulación tiene lugar poco antes del secado en un tambor rotatorio, que la mayoría de las veces representa la primera parte del horno giratorio [30], [81], [96], [97] y [108]. El material moldeado sobre platos granuladores se lleva previamente a un canal de secado o a un tambor secador [30] y [117].

La expansión de los gránulos se efectúa en distintos tipos de hornos, que han de estar adaptados no sólo a la primera materia en cada caso, sino también a las ulteriores propiedades exigidas a los granulados. Así, existen:

- hornos rotatorios tubulares [2], [6], [12], [16], [20], [22], [29], [38], [53], [56], [63], [64], [67], [76], [77], [81], [86], [91], [123], [127] [132], [139], [146], y [150];

- parrillas sintetizadoras [7], [12], [13], [18], [20], [27], [32], [33], [34], [37], [41] y [45];

- cintas sintetizadoras (en parte hornos de solera giratoria) [11], [46], [112] y [129];

- métodos de circulación en corriente [120] y [126];

- hornos verticales [130] y [118];

- métodos de vibración [117];

- métodos de corriente turbillonaria [90].

Algunos de estos sistemas de expansión serán tratados a continuación con más detalle.

Como es sabido, los hornos rotatorios se utilizan la mayoría de las veces para tamaños muy distintos. Se distingue entre hornos rotatorios de una pieza y de dos piezas, que son de una longitud de 12 a $80 \mathrm{~m}$ y pueden tener diámetros de 1 a $3,5 \mathrm{~m}$. Para la producción de KERAMSIT se emplean normalmente hornos de 15 a $30 \mathrm{~mm}$; para la producción de HAYDITE, de 20 a $30 \mathrm{~m}$, y en el método LECA, de 60 a $75 \mathrm{~m}$ de longitud [130]. Los hornos rotatorios funcionan según el método de contracorriente, es decir, los gases fluyen en contra de la corriente de gránulos crudos. Como consecuencia resulta que en el extremo de alimentación puede medirse una temperatura de unos $400^{\circ} \mathrm{C}$ y en el otro extremo del horno del orden de $1.150^{\circ} \mathrm{C}$. El material camina desde el extremo de alimentación en dirección a la zona de altas temperaturas (zona de expansión), mientras que granula debido a la rotación del horno, se seca y se expande. Cadenas colgadas han de evitar que se peguen los diversos gránulos. Como combustible se emplea fuel-oil, carbón, una mezcla de fuel-oil y polvo de carbón o gas de alumbrado o gas natural.

Fl método LECA es el sistema más empleado para la producción de productos de arcilla expandida a partir de arcilla, arcilla de esquisto y esquisto arcilloso, en Europa Central. 
El horno rotatorio que se utiliza está subdividido en una zona de conformación y secado con una velocidad de rotación de 3 a 6 r.p.m. y $2,5 \mathrm{~m} \varnothing$ y una zona de cocción que marcha de 6 a 9 r.p.m. y tiene 3,5 $\mathrm{m}$ de diámetro. El rendimiento total del horno es de unos 350-500 $\mathrm{m}^{3}$ de arcilla expansiva por día. Las densidades aparentes conseguidas son: para los gránulos de 0 a $3 \mathrm{~mm}$, de $600-800 \mathrm{~kg} / \mathrm{m}^{3}$; con $3-10 \mathrm{~mm}$, de $350-500 \mathrm{~kg} / \mathrm{m}^{3}$, y con 10 a $20 \mathrm{~mm}$, de $270-400 \mathrm{~kg} / \mathrm{m}^{3}$. La figura 2 muestra el esquema de una instalación para la fabricación de LECA.

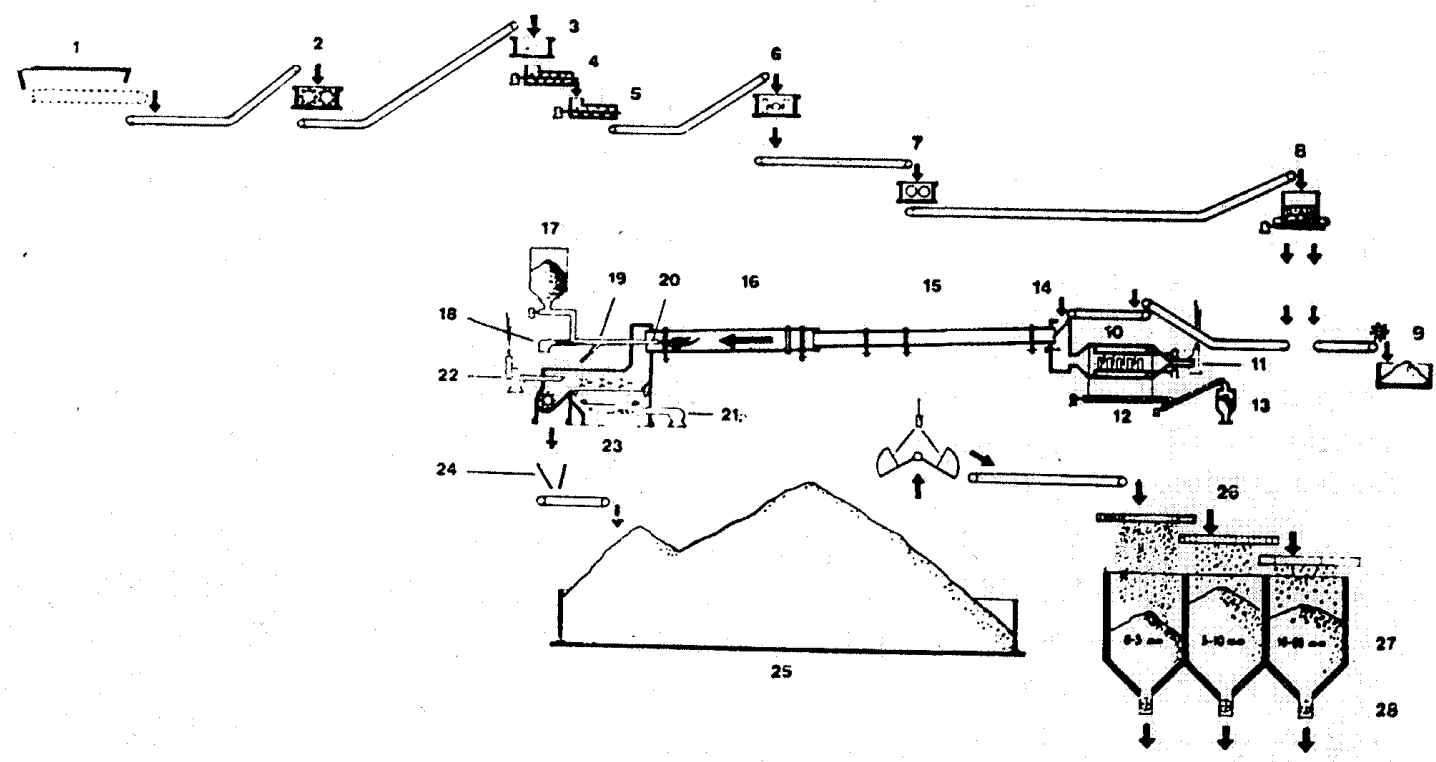

Fig. 2.-Esquena de fabricación del LECA, segun Hunziker A. G.

1. Apartador del crudo (Arcilla).

2. Quebrantadora.

3. Triturador primario.

4. Amasadora de doble efecto I.

5. Amasadora de doble efecto II.

6. Molino de rodillos.

7. Molino de finos.

8. Alimentador rotatorio del tamiz.

9. Depósito de reserva.

10. Electrofiltro.
11. Ventilador para los gases de escape de la chimenea.

12. Transportador para la eliminación de polvos.

13. Silo para el polvo.

14. Alimentador del horno.

15. Horno, zona de secado.

16. Horno, zona de cocción.

17. Silo para el carbón.

18. Alimentador de carbón.

19. Alimentador de petróleo.

20. Tobera.
21. Aire de refrigeración.

22. Ventilador de gases de escape.

23. Enfriador de parrilla.

24. Medidor volumétrico de la producción.

25. Depósito intermedio.

26. Estación clasificadora.

27. Silo de almacenamiento.

28. Medidor en volumen para la venta.

Ultimamente en la República Federal se acoplan a los hornos rotatorios diversos precalentadores para el secado y calentamiento previo, a fin de poder dirigir mejor el curso de la temperatura en las diversas secciones de cocción o dirigirlo independientemente en los dos aparatos. La casa Krupp emplea para ello un precalentador vertical [150], en tanto que la casa MIAG, además de un precalentador vertical sencillo o doble, usa también los llamados precalentadores de parrilla [131]. La figura 3 presenta un horno rotatorio combinado con un precalentador de parrilla.

En los países de la Europa oriental la producción de KERAMSIT se efectúa también en hornos rotatorios, que en esencia son similares al principio LECA. Como quiera que para 
este método se emplea casi exclusivamente arcilla, la fabricación de los gránulos se realiza normalmente con una prensa provista de boquilla perforada. La figura 4 muestra una fábrica de KERAMSIT cerca de Stalingrado (URSS).

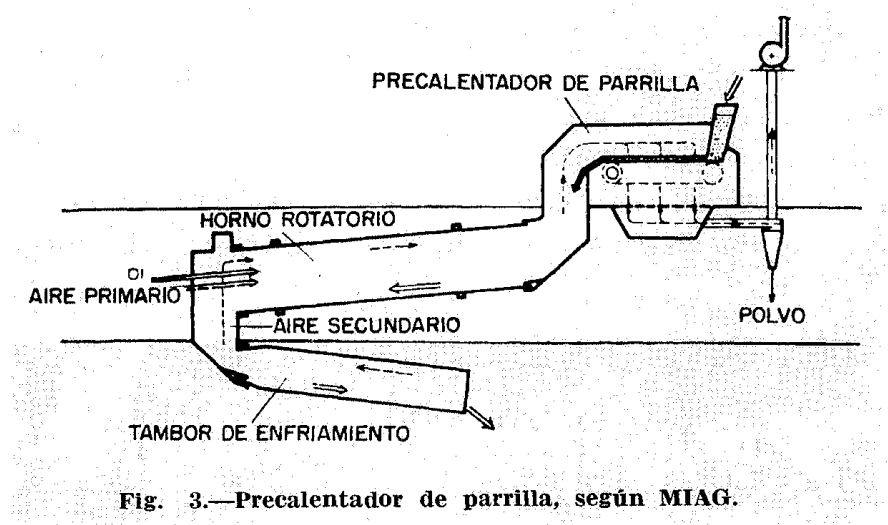

Según Walz y Wischers, en ultramar se emplea, más bien por motivos de economía, arcilla de esquisto en las fábricas de nueva planta. De una relación del año 1961 puede deducirse que en EE.UU. y Canadá el $65 \%$ de las fábricas de arcilla expandida con horno rotativo emplean como materia prima arcilla esquistosa, el $29 \%$ arcilla y el $6 \%$ esquisto arcilloso [97]. Como se ha dicho, arcilla esquistosa y esquisto arcilloso, la mayoría de las veces, sólo se fragmentan en las trituradoras habituales y se criban, consiguiéndose los tamaños de gránulos deseados. Los ripios de arcilla expandida, producidos casi exclusivamente en el horno rotatorio, se trituran después del proceso expansivo y se descomponen en distintos tamaños de grano. En la figura 5 se representa el esquema de una instalación de esquisto expansivo para la producción de HAYDITE.

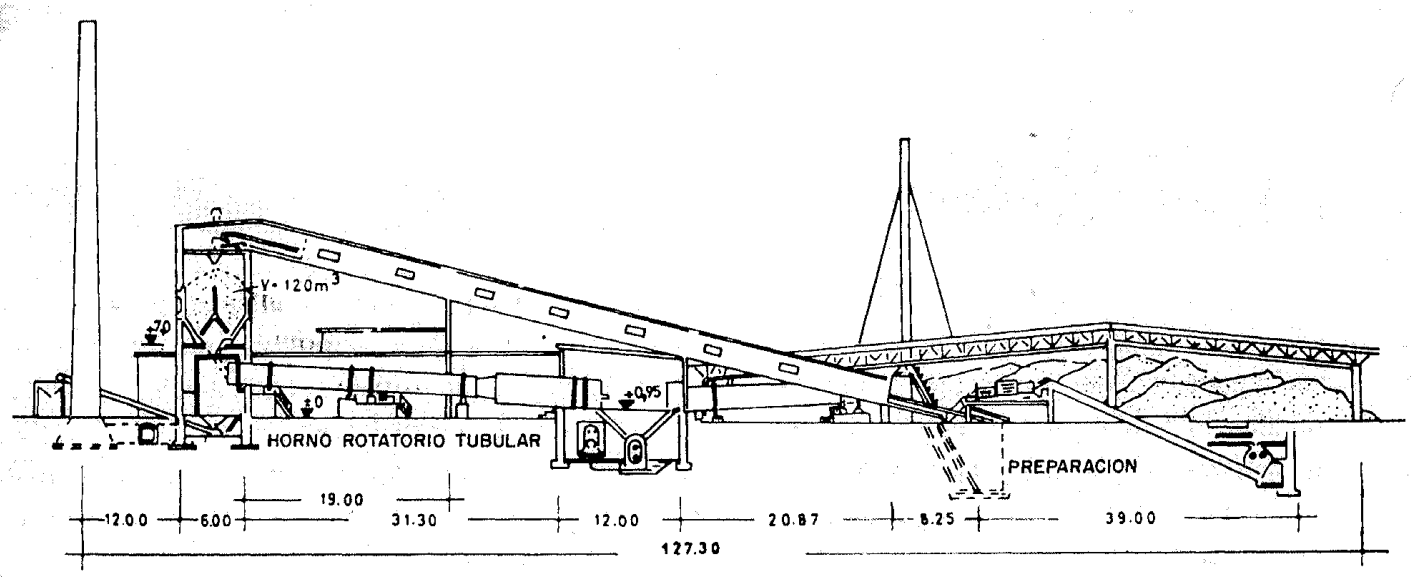

Fis. 4.-Proceso del Keramsit, según steinicke.

El método de parrilla sinterizadora se aplica preferentemente en EE.UU. para la producción de maslita, shalita, etc. [130]. En contraposición a la explotación con hornos rotatorios, en donde el combustible se lleva desde el exterior, en este método se mezcla el com- 
bustible sólido con la materia prima. El material previamente granulado se alimenta con el combustible directamente a una cinta sinterizadora continua y se pasa bajo la caperuza del quemador: En esta zona existen unos aspiradores bajo la cinta que mueven hacia abajo, el aire caliente, con lo que se sinterizan los gránulos. La ventaja de estas instalaciones con respecto al método del horno rotatorio, consiste en que la materia prima no sólo se calienta con extraordinaria rápidez hasta la temperatura de expansión, sino que también los gases de la expansión no pueden escaparse con tanta rapidez. Como consecuencia resulta que también las materias primas lentas de expansión pueden aprovecharse bien. Según la clase de materia prima y el control de la instalación se consiguen por día de 12 a $18 \mathrm{t} / \mathrm{m}^{2}$ de superficie de cinta [130], siendo las densidades aparentes de 600 a $1.100 \mathrm{~kg} / \mathrm{m}^{3}$. La figura 6 muestra una instalación de cinta sinterizadora LURGI que funciona con gas.

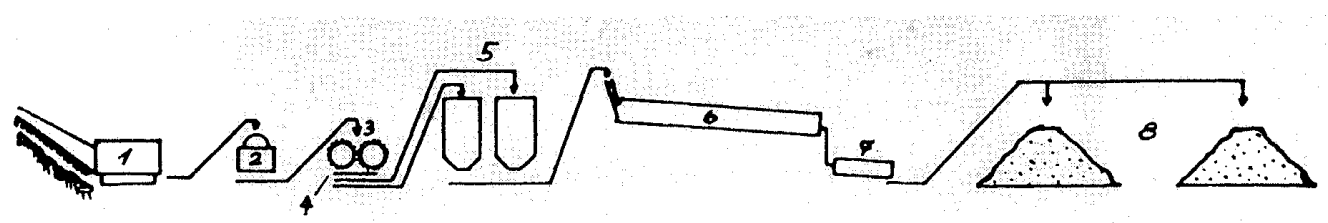

Fig. 5.-Esquema de una instalación para pizarras dilatadas, según Steindl.

1. Excavadora de cantera.

2. Machacadora de mandíbulas.

3. Quebrantadora de cilindros.

4. Tamizadora de sacudidas.
5. Silos de almacenamiento.

6. Horno rotatorio.

7. Enfriador de tambor.

8. Apilamiento de material terminado.

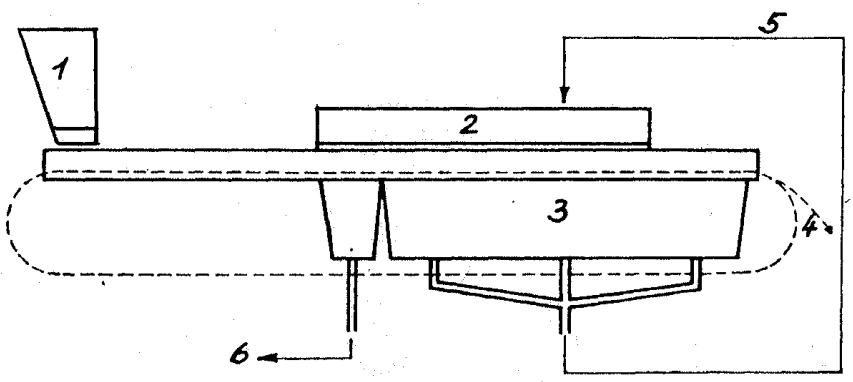

Fíg. 6.-Instalación de cinta sinterizadora que funciona con gas, según SteindI.

1. Alimentación.

2. Cubierta del horno.

3. Caja del aspirador.

Con arreglo a un principio muy parecido trabajan las llamadas cintas sinterizadoras, en las que la cinta está constituida por una cadena articulada con soportes de chapa de acero, en la que, sobre placas de chamota, se expanden los gránulos, mientras la cinta atraviesa un horno-túnel de pequeña sección transversal. La cinta tiene una longitud de $3 \mathrm{~m}$ y la velocidad de paso más favorable para el material a expandir es de 6 a 8 minutos [41]. Una derivación de este sistema la representa el horno de carrusel y solera giratoria, en el que la materia prima granulada o fragmentada gruesa se lleva a un lecho de calcinación o de sinterizado a modo de carrusel a través de un horno de calcinación [11], [112] y [115]. Normalmente, la torta sinterizada hay que machacarla a continuación al tamaño de granulación deseado.

La producción de arcilla expandida con arreglo al método de circulación-corriente tiene lugar en un horno cilíndrico dispuesto verticalmente, que por abajo termina en forma 
de embudo. Por esta parte, los gases se insuflan con una velocidad tan grande que arrastran hacia arriba el granulado que hay en la periferia del horno. Puesto que el chorro de gas se hace más débil a medida que se sube en el horno, los gránulos vuelven a caer hacia abajo, en donde la circulación empieza de nuevo. El proceso de calcinación tiene lugar en intervalos de 40 segundos. La calcinación puede efectuarse con aceite ligero, aceite pesado o gas [120] y [126]. El rendimiento del horno es de $200 \mathrm{t}$ ó $400 \mathrm{~m}^{3}$ por día, con un peso aparente de $500 \mathrm{~kg} / \mathrm{m}^{3}$. El consumo de calor es de $950 \mathrm{WE} / \mathrm{kg}$ arcilla expandida [117]. Un esquema de una instalación de arcilla expandida según el método de circulación-corriente es el que se muestra en la figura 7.

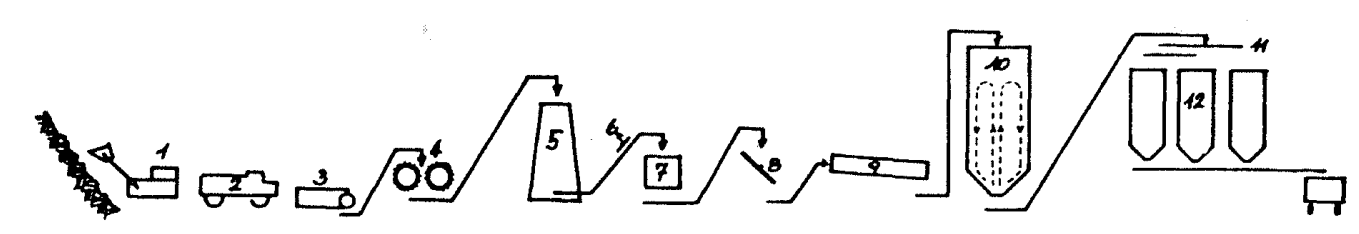

Fig. $i$-Instalación para la dilatación de arcillas por el procedimiento de fabricación ZS, según Steindl.

1. Equipo de cantera.

2. Transporte.

3. Alimentador.

4. Quebrantadora de cilindros.

5. Silo de arcilla.
6. Separador de metales.

7. Equipo regulador para la arcilla.

8. Granulador de plato.

9. Secador rotatorio.
10. Horno con circulación en contra corriente.

11. Tamizadoras.

12. Silos.

Con el método SELAS [92] y [118], pequeños gránulos cilíndricos se secan en vía balística con aire caliente procedente del horno de expansión. El material seco llega a través de una cinta transportadora, por una tolva de carga, al horno de cuba calentado con fuel-oil, donde primeramente se expande sobre un lecho de aire caliente hasta aproximadamente $400^{\circ} \mathrm{C}$ y a continuación por caída libre. Este sistema es apropiado para arcillas con un punto de fusión de unos $1.600^{\circ} \mathrm{C}$ y más. Los pesos aparentes conseguidos son de $440 \mathrm{~kg} / \mathrm{m}^{3}$.

Una forma totalmente distinta de la producción de arcilla expandida la representa la fabricación de bloques. Para ello se tritura, en parte, el granulado de arcilla expandida producido previamente. Más tarde se mezcla con arcilla aglutinante hasta $40 \%$ y se moldean bloques de tamaño $20 \times 20 \times 40 \mathrm{~cm}$ o similares. La cocción de estos bloques, en parte vidrificados, se realiza, la mayor parte de las veces, en horno-túnel. El peso aparente es de $0,77 \mathrm{~kg} / \mathrm{dm}^{3}$ y la resistencia a la compresión de unos $85 \mathrm{kp} / \mathrm{cm}^{2}$ [14], [19], [38], [43], [65], [69] y [73].

En la URSS se emplea el método "bloque de Keramsit" y el método "Keramsita esponjosa". Según el primer método los bloques de arcilla, extrusionados en cápsulas, se calcinan en cinta sinterizadora, mientras que, con arreglo al segundo método, las tortas extrusionadas $(42 \times 24 \times 3 \mathrm{~cm})$ atraviesan un horno calentado con gas ciudad y seguidamente se asierran [31] y [62]. En Alemania tiene lugar la producción de bloques de arcilla expansiva aportando un aglomerante cerámico [144] y prensando el granulado caliente recién expandido en moldes metálicos [143].

\section{POSIBILIDAdes de APLiCACION DE PRODUCTOS DE ARCILla EXPANDIDA}

Puesto que las posibilidades de aplicación dependen esencialmente de las propiedades es- 
peciales de los productos de arcilla expandida, se indicarán a continuación brevemente algunas propiedades de los granulados de este material:

a) Peso aparente y valores de aislamiento [130]:

\begin{tabular}{|c|c|c|c|}
\hline $\begin{array}{c}\text { Tamaño de grano } \\
\text { (mm) }\end{array}$ & $\begin{array}{l}\text { Peso aparente } \\
\left(\mathrm{kg} / \mathrm{m}^{3}\right)\end{array}$ & $\begin{array}{r}\text { Coeficiente } \\
\text { térmica }\end{array}$ & $\begin{array}{l}\text { de conductibilidad } \\
\text { (keal/m } / \mathrm{h} \cdot{ }^{\circ} \text { ) }\end{array}$ \\
\hline $0-3$ & 656 & & 0,088 \\
\hline $3-10$ & 393 & & 0,099 \\
\hline $10-15$ & 353 & & 0,091 \\
\hline $15-20$ & 311 & & 0,083 \\
\hline
\end{tabular}

b) Capacidad de absorción de agua [96] y [108]:

1) gránulo bien sinterizado con superficie cerrada: casi ninguno;

2) otros: 2-15\% de volumen.

c) Resistencias a la compresión [96] y [103]:

- hormigones puros de arcilla expandida: $10-350 \mathrm{kp} / \mathrm{cm}^{2}$;

- resistencias habituales: alrededor de $75 \mathrm{kp} / \mathrm{cm}^{2}$.

d) Insonorización [96]:

- ladrillos de medianería de $10 \mathrm{~cm}$ :

- $10-3.200 \mathrm{~Hz}=48 \mathrm{~dB}$;

- $550-3.200 \mathrm{~Hz}=57 \mathrm{~dB}$.

e) Resistencia a las heladas con superficie cerrada del gránulo [96]: - muy buena.

f) resistencia al fuego [130]:

- una pared de $10 \mathrm{~cm}$ de espesor de hormigón de arcilla expandida es, según DIN 4102, "muy resistente al fuego".

La arcilla expandida se distingue en general por su poco peso y por su elevado valor de aislamiento. En virtud de estas propiedades, este material no sólo se ofrece a granel, sino también en hormigón para el aislamiento térmico y como hormigón ligero para construcción. Como posibilidades de aplicación se citan, entre otras:

- a granel para aparatos de calefacción y refrigeración [15] y [108];

- capas aislantes intermedias en la construcción de carreteras [97] y [108] ;

- material de relleno para mortero de revestimiento [108];

- insonorización de edificaciones antiguas [95];

- hormigón monograno para objetos de aislamiento [86] y [130];

- construcciones de pisos [112] y [130];

- construcciones de cubiertas planas [86], [104], [108], [112] y [130];

- ladrillos huecos y bloques [14], [19], [38], [43], [65], [69], [73], [108], [122], [130], [142], [143] y [144];

- ladrillos macizos [108] y [130];

- ladrillos de encofrado [130]; 
- ladrillos de medianería [122] y [130];

- ladrillos para colectores de humos [108] y [130];

- piezas acabadas [5], [40], [79], [86], [108], [116], [130] y [149];

- hormigón ligero para construcción de edificios elevados, cubiertas, puentes, etc. [80], [87], [94], [97], [98], [99], [101], [102], [105], [107], [108], [109], [110], [113], [124], [130], [138], [140] y [147].

La relación de posibilidades de aplicación de productos de arcilla expansiva en el ramo de la construcción no está con esto ni con mucho agotada, porque presentan casi diariamente nuevos sectores de aplicación.

Como se ha dicho, la arcilla expandida para aislamiento no sólo se utiliza a granel, sino también con ligera aglomeración con cemento como hormigón aislante. Para espesores de menos de $6 \mathrm{~cm}$ se emplean los tamaños $3-10 \mathrm{~mm}$ y para espesores de más de $6 \mathrm{~cm}$ los tamaños de hasta $20 \mathrm{~mm}$. La consistencia más favorable se consigue con una relación agua/ /cemento de 0,5 a 0,6. Según el tamaño de grano empleado y la compactación, se logran pesos aparentes de 600 a $750 \mathrm{~kg} / \mathrm{m}^{3}$, coeficientes de conductibilidad térmica en estado seco de 0,12 hasta $0,16 \mathrm{kcal} / \mathrm{m} \cdot \mathrm{h} \cdot{ }^{\circ} \mathrm{C}$ y, después de 28 días, resistencias a la compresión de 15 a $25 \mathrm{kp} / \mathrm{cm}^{2}$ [86]. La figura 8 muestra la sección transversal de un hormigón aislante LECA.
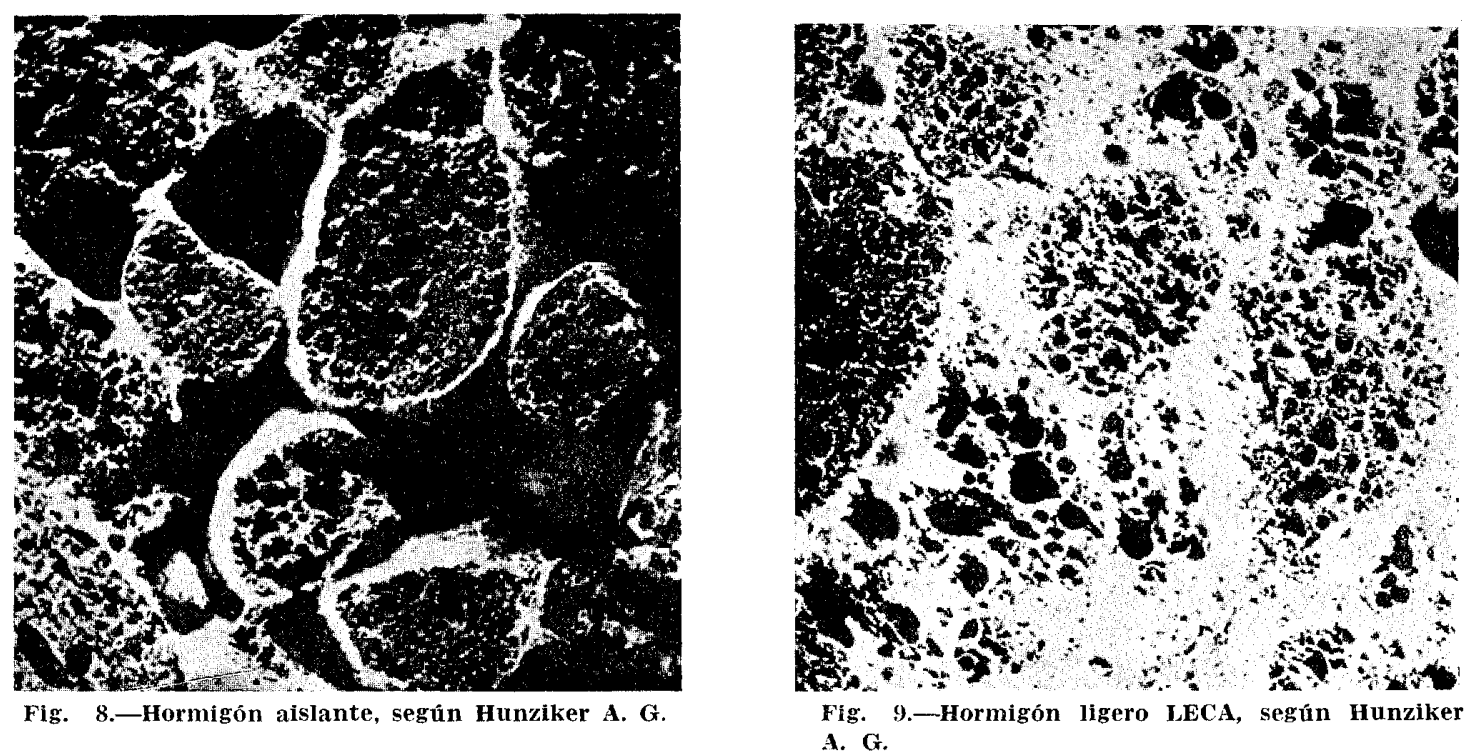

Pueden encontrarse hormigones ligeros LECA con resistencias a la compresión de unos $1.000 \mathrm{~kg} / \mathrm{m}^{2}$ obtenidos por mezcla óptima del granulado 0 a $20 \mathrm{~mm}$ y $300 \mathrm{~kg}$ de cemento. La mezcla se compone de:

- $40 \%$ de volumen de granos de 0 a $3 \mathrm{~mm}$;

- $35 \%$ de volumen de granos de 3 a $10 \mathrm{~mm}$;

- $25 \%$ de volumen de granos de 10 a $20 \mathrm{~mm}$.

El coeficiente de conductibilidad térmica se encuentra entre 0,20 y $0,24 \mathrm{kcal} / \mathrm{m} \cdot \mathrm{h} \cdot{ }^{\circ} \mathrm{C}$. La figura 9 muestra la sección transversal de un hormigón ligero LECA. 


\section{ECONOMIA}

Los áridos de arcilla o arcilla esquistosa expandida permiten una reducción de peso de hasta $30 \%$ en la producción de hormigón ligero y, en el hormigón aislante, una disminución de peso de hasta $80 \%$ [6]. Sólo en el transporte y el montaje de piezas acabadas se obtienen, como consecuencia, notables economías. Como lo demuestra una comparación de costos de una casa de 12 plantas de hormigón pesado y hormigón ligero, se pudieron economizar 7,72 DM por $\mathrm{m}^{2}$ de superficie de cubierta en marcos, techos y cimentación por pilotes [97]. Al utilizarse arcilla expandida en las placas de la calzada del puente de la bahía de Oakland en San Francisco, se comprobó que se pudo ahorrar el $5 \%$ del costo [106]. Según Steinicke [108], este material de construcción se ha impuesto últimamente en EE.UU. sólo porque presentaba:

1. Buenas propiedades para la venta.

2. Aplicación universal.

3. Fáciles posibilidades de elaboración.

4. Buen margen de beneficios.

Como quiera que casi todas las instalaciones para la obtención, preparación y producción de gránulos pueden ser las de una fábrica de ladrillos, es absolutamente rentable la transformación de una explotación ladrillera en una fábrica para la producción de productos de arcilla expandida [108] y [137]. Como resultado de un estudio crítico de la producción de áridos ligeros en una fábrica de ladrillos americana, la asociación de una fabricación de arcilla expandida a una fábrica de cerámica de construcción puede ser más ventajosa que la sola producción de aquélla [84].

Según cálculos de una casa alemana constructora de hornos en el año 1968 [131], es necesario un capital de 45-75 DM/t/año de arcilla expandida. El costo de producción para la obtención de $1 \mathrm{~m}^{3}$ es: para un peso aparente de 0,3 a $0,4 \mathrm{~kg} / \mathrm{l}$, de $10-14 \mathrm{DIM}$, y para un peso aparente de 0,6 a $0,7 \mathrm{~kg} / l$, de 17-22 DM. La producción diaria debe ser, por lo menos, de $250 \mathrm{t}$, ya que en instalaciones más pequeñas según la experiencia se producen mayores gastos específicos [131]. El costo medio de producción de granulados de arcilla expandida (inclusive todos los gastos anejos, tales como amortización de maquinaria y construcciones, servicio del capital y gastos de personal, combustible, corriente, agua, lubricantes, grasas, reparaciones, repuestos, etc.) es, según los datos suministrados por otra casa constructora de hornos en la Feria de Hannóver en abril de 1970 [152], para las diferentes instalaciones productoras, de aproximadamente:

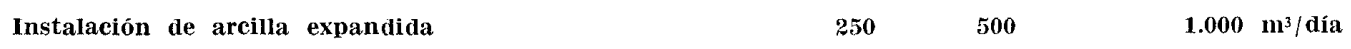

Costo de producción.

De aquí resulta para arcilla expandida de 0,4 $\mathrm{kg} / \mathrm{l}$.

Para arcilla expandida de $0,5 \mathrm{~kg} / \mathrm{l}$.

$\begin{array}{ccc}41,00 & 33,00 & \begin{array}{r}28,00 \mathrm{DM} / \mathrm{t} \text { de arcilla } \\ \text { expandida. }\end{array} \\ 16,40 & 13,20 & 11,20 \mathrm{DM} / \mathrm{m}^{3} \\ 20,50 & 16,50 & 14,00 \mathrm{DM} / \mathrm{m}^{3}\end{array}$

\section{BREVE RESUMEN}

Después de un repaso al desarrollo general de la obtención de arcilla expandida, se cita una extensa bibliografía nacional y extranjera obtenida desde el año 1948. Para esta or- 
denación bibliográfica se tuvieron en cuenta 152 publicaciones. A pesar de que es discutible el primer titular de patente para la producción de productos de arcilla expandida como material de construcción, los primeros granulados elaborados según la técnica de la construcción se han producido según una patente americana de Hayde en el año 1918. Se han tratado aquí las condiciones previas de la materia prima, los procesos durante el tratamiento expansivo y la influencia de distintos auxiliares de la expansión y reguladores en ios granulados de arcilla expandida. Además de los métodos más importantes de producción, se tratan también los diferentes métodos expansivos, haciéndolo con más detalle para los métodos de horno rotatorio, de parrilla sinterizadora, de circulación-corriente y el método SELAS.

Las diversas posibilidades de aplicación de granulados y gravilla de arcilla expandida se presentan, de un lado, en el campo del aislamiento $\mathrm{y}$, del otro, para el hormigón ligero en construcción. Por último, se trata brevemente de la economía en relación con la producción y utilización de los productos de arcilla expandida.

\section{B I B L I O G R A F I A}

[1] Coniey, J. E., H. Wilson und T. A. Klinefelter: "Die Herstellung von Leichtzuschlagstoffen aus Tonen, Tonschiefern, Schiefern und anderen Materialien", United States Departement of the

[2] Klinefelter, Hancock und Hamlin: „Prüfung von Tonen auf ihre Eignung als Leichtbau-Zuschlagstoffe", The British Clayworker 59 (1950). Nr. 671, S. 157-158, 1 Abb., 1 Tab.

[3] Riley, Ch. M.: „Verhältnis der chemischen Eigenschaften zum Blähen von Tonen". Journal of the Amer. Cer Soc. 34 (1951) Nr. 4, S. $121-128,4$ Abb., 3 Tab., 19 Ref.

[4] Riley, Ch. M.: "EinfluB der chemischen Eigenschaften auf das Blähen der Tone". The British Clayworker (1951). Nr. 3

[5] Bell und McGinnis: Entwicklung großer keramischer Leichtbauteile". The British Clayworker LX (1951), Nr. 713, S. 145-148. 5 Abb.

[6] Matthews: "Geblähte Tone und Schiefertone ais Leichtzuschläge", Trans. of the Can. Inst. of Mining Met. 54 (1951), S. 489-492

[7] Bell: Blähen von Tonen zwecks Herstellung von Leichtzuschlägen". "Brick \& Clay Rec. 120 (1952), Nr. 1, S. 46, 49 und 52, 5 Abb.

[8] Anon: "Ton-Hohlkügelchen, ein neuer Leichtzuschlagstoff", Brick \& Clay" Rec. 121 (1952), Nr, 4, S. 46-47, 3 Abb.

[9] Bergmann, K.: „Schaumton", Osterr. Zieglerzeitung (1952). Nr. 12

(10) Meyer, K.: "Industrielle Erzeugung von Zuschlagstoffen für die Herstellung "von Leichtbeton aus Ziegellehm oder ähnliche Rohstoffen", Tonind.-Ztg. 76 (1952), H. 1/2, S. 2-8

[11] Anon.: " Sinteranlage für Leichtzuschläge aus Ton", Brick \& Clay Rec. 123 (1953). Nr. 2, S. 50-51, 4 Abb

[12] Wilson, H.: .Leichtzuschläge für die Bauindustrie", Journ, of the Can. Cer. Soc. 22 (1953), S. 44 ff., 6 Abb., 2 Tab.

[13] Hardy: "Vorstudien für die Herstellung gebrannter Ton-Leichtzuschläge", Amer. Cer. Soc. Bull. 33 (1954), Nr. 7, S. 201-203, 1 Abb.

[14] Anon.: "Neuartiger keramischer Leichtblock", Amer. Cer. Soc. Bull. 33 (1954), Nr. 7, S. 218, 2 Abb.

[15] Vlaanderen, J. F.: "Blähton“, Cement 6 (1954), Nr. 23/24, S. 406 bis 109

(16) Lenhart, W. B.: "Leichtzuschläge aus, geblähtem Schieferton", Rock Products 57 (1954), Nr. 1, S. 143-146 u. 149. 9 Abb.

[17] Maarbjerg, M.: "LECA-Blähton als Isolierstoff", Lerindustrien. Kopenhagen( 1954), Nr. 2, S. 52-55 (Referat: "Ziegelindustrie [1954], S. 932)

[18] Anon.: "Neues Werk zur Herstellung von Leichtzuschlägen aus Ton". Brick \& Clay Rec. 124 (1954), Nr. 2, S. $51-53,10$ Abb.

19] Anon.: .Neuer vollkeramischer Leichtbaustein", Brick \& Clay Rec. 124 (1954), Nr. 3, S. 39 und 111, 2 Abb.

[20] Wilson, H.: "Leichtzuschläge für die Bauindustrie", The British Clayworker LXII (1954), Nr. 742, S. 331-332 und Nr. 743, S. 377 bis 378,2 Abb., 2 Tab.

[21] Singer, F., und $S$. S.: „Fortschritte in der Herstellung poröser und hohler baukeramischer Erzeugnisse". The British Claywor ker LXIII (1954), Nr. 745, S. 55-59, 4 Tab., 23 Ref.

[22] Wilson, H.: .Entwicklung der Herstellung von Ton-Leichtzuschlägen in Kanada", The British Clayworker LXIII (1954), Nr. 750, S. $218-219,1 \mathrm{Abb}$

[23] Anon.: "Steigende Herstellung von Ton-Leichtzuschlägen", Brick \& Clay Rec. 127 (1955), Nr. 5, S. 47-50, 8 Abb

[24] Stedham: "Tonsinterung: Labormäßige Herstellung von Blähtonzuschlägen und Fertigerzeugnissen", Trans. of the Br. Cer. Soc. 55 (1956), Nr. 2, S. 113-139, 9 Abb., 1 Tab., 30 Ret.
[25] Anon.: „Englisches Tonsinterwerk nach dem Aglite-Verfahren" The British Clayworker 65 (1956), Nr. 771, S. 95-97, 4 Abb.

(26) Anon.: "Die Tonkügelchenbildung", Brick \& Clay Rec. 128 (1956), Nr. 3, S. 57,1 Abb.

[27] Anon.: "Wachsender Absatz von Ton-Leichtzuschlägen", Brick \& Clay Rec. 129 (1956), Nr. 3, S. 62-63 u. 65, 7 Abb.

28] Anon.: "Kontinuierlich arbeitendes Tonsinterwerk", Brick \& Clay Rec. 129 (1956), Nr. 5, S. 40-41, 7 Abb

[29] Kristen, Th.: "Versuche mit Blähton aus deutschem Ton", Zement-Kalk-Gips (1956), H. 2

[30] Schätzer, L.: "Keramische Zuschlagstoffe für Leichtbeton", Silikattechnik 7 (1956). Nr. 6, S. 224-226, 8 Abb., 7 Tab.

(31) Kalb und Wilhelm: "Schaumkeramik", Silikatind. (1956), Nr. 8 , S. $329-330,4 \mathrm{Abb}$.

[32] Dunham, H.: „Die Merstellung von Blähton-Leichtzuschlägen nach dem Sinterrost-Verfahren", Claycraft 31 (1957), Nr. 3, S. 78-82, 6 Abb. [33] Catchpole, F.: "Die Herstellung von Tonleichtzuschlägen nach
dem Sinterrostverfahren". Trans. Br. Cer. Soc. 56 (1957), Nr. 10, S. $519-528,7 \mathrm{Abb}$.

[34] Pfeiffenberger, L. E.: „Probleme bei der Herstellung von Tonleichtzuschlägen nach dem Sinterrostverfahren", Amer. Cer. Soc. Bull. 36 (1957). Nr. 7, S. 272-275, 4 Abb.

[35] Steinicke, K. H.: "LECA-Blähton, ein vielfach verwendeter neuer Baustoff", Bauwelt 48 (1957), Nr. 17, S. 390-391

[36] Ehlers, E. G.: „Der Mechanismus der Bildung von Tonleichtzuschlägen", Amer. Cer. Soc. Bull. 37 (1958), Nr. 2, S. 95-99, 4 Abb., 3 Tab

[37] Anon.: "Neues Sintertonwerk", Brick \& Clay Rec. 132 (1958), Nr. 1 , S. $46-47$ u. 49,7 Abb.

[38] Anon.: "Die Herstellung tongebundener Blöcke aus Blähtonen", Brick \& Clay Rec, 133 (1958), Nr. 1, S. 48-49, 51 u. 58, 4 Abb.

39] Anon.: "Wie der Burns Brick Block hergestellt wird", Brick \& Clay Rec. (1958), S. 49-51

[40] Stanzak, W.: "Herstellung von Keramsit in der Tschechoslowakei", Silikattechnik" 9 (1958), Nr. 4, S. 169-170, 3 Abb.

(41] Kaempfe, F.: „Zur Frage des Blähtons", Zement-Kalk-Gips 11 (1958), Nr. 10, S. 437-442. 6 Abb., 1 Tab.

[42] Cernjak, J. N.: .Uber die physikalischen Grundlagen des Aufblähprozesses von leichtschmelzenden Tonen und Schaumglas", Steklo i Keramika 15 (1958), H. 10, S. 25-28

[43) Goodman, Ch.: "Die Entwicklung von Leichtblöcken mit TonGoodman, Ch.: "Die Entwicklung von Leichtblocken
bindung", Brick \& Clay Rec. 134 (1959), Nr. 5, S. 56-57

[44] Everhardt. J. E.: "Die Prüfung von Tonen und Tonschiefern auf ihre Eignung zur Herstellung von Leichtzuschlägen", Brick \& Clay Rec. 134 (1959), Nr. 5, S. 58-59 u. 86, 4 Abb.

[45] Tinker, D.: „Die handelsmäßige Herstellung tongebundener Tinker, D.: "Die handelsmäßige Herstellung tongebundener
Leichtsteine", Brick \& Clay Rec. 134 (1959). Nr. 6, S. 60 und 62

[46] Anon.: Entwicklung und Zukunftsaussichten von Ton-LeichtAnon.: "Entwicklung und Zukunftsaussichten von
blöcken". Brick \& Clay Rec. 134 (1959), Nr. 4, S. 63-65

[47] Caruso, A.: "Uber die Herstellung longebundener Leichtsteine", Brick \& Clay Rec. 134 (1959), Nr. 4. S. 69 ff., 3 Abb., 2 Tab

[48] Ehiers, E. G.: „Uber den Mechanismus beim Aufblahen von Tonen und Leichtzuschlägen", Amer. Cer. Soc. Bull. 37 (1958), Nr. 2 S. 95-99, 4 Abb., 3 Tab. (Kurzreferat: Zl 1959, Nr. 6. S. 173 )

[49] Fastabend, H., und J.-L. Ruyter: "Untersuchungen über die
Bläheigenschaften von Marschtonen", Tonind.-Ztg. 83 (1959), H. 22 , S. $532-535$

[50] Tschernjak, J. N.: „Ober die physikalischen Grundlagen des Blähprozesses", Silixattechnik 10 (1959), H. 3, S. 98 
[51] Anon.: "Gebrannte Tonaggregate für den Straßenbau", Brick \& Clay Rec. 135 (1960), Nr. 7, S. 39-90, $3 \mathrm{Abb}$.

[52] Anon.: "Herstellung hochwertiger Tonleichtzuschläge", Brick 8 Clay Rec. 136 (1960). Nr. 2, S. 44-45, 5 Abb.

[53] Mohler, N. F.: Tonleichtzuschlag-Herstellung nach dem Drehrohrofenverfahren", Brick \& Clay Rec. 136 (1960), Nr. 6, S. 90-92 $96-97$ und 104, 6 Abb.

[54] Mohler, N. F.: "Die Entwicklung der Haydite-Produktion", Brick \& Clay Rec. 137 (1960), Nr. 2, S. $40-42$ und 67,4 Abb.

[55] Svec, J. J.: "Tongebundene Leichtblöcke", Brick \& Clay Rec. 137 (1960), Nr. 4. S. $49-50$ und 83

[56] Steinicke, K. H.: "Herstellung, Anwendung und Wirtschaftlichkeil des Blähton-Betons", Dissertation, TH Karlsruhe 1960

[57] Blymen, L. H.: "Die physikalisch-chemische Natur des Blähen von Tonen - die Bildung von Keramsit", Steklo i. Keramika 17 (1960). Nr 2, S. 32-36

[58] Pavlov, V. F.: "Einfluß der Ánderung der Viskosität von leichtschmelzenden Tonen im Intervall von $800-1200^{\circ} \mathrm{C}$ auf das $\mathrm{Sin}$ tern und Aufblähen", Steklo i Keramika 17 (1960), H. 3, S. 21-25, 1 Ref

[59] Hill, R. D., und D. N. Crook: „Einige Gründe für das Aufblähen von Blähtonkörnern", Australian J. Appl. Sc. 11 (1960), H. 3 S. $374-384$

[60] White, W. H.: ,Untersuchungen über die Eignung von Tonen zur Blähtonherstellung", Illinois State Geol. Survey Circ. (1960) Nr. 290 (Kurzreferat: Techn. Mitt. Bundesv. dt. Ziegelindustrie Nr. 4/1961)

[61] Lucke, K. H.: „Untersuchungen über den Blähvorgang bei Tonschiefer", Silikattechnik 11 (1960), Nr. 7, S. 300-301, 6 Ref

[62] Hanke, H.: "Die Technologie der neven Blähtonwerke", Silikat technik 11 (1960), Nr. 7, S. 302-304

[63] Malzew, W., und N. Dikermann (Ubers. Dipi,-ing. Böhm) "Schaumkeralit (Keramsit), ein neuer Baustoff", Die Ziegelindustrie 13 (1960), H. 8, S. 234-237

[64] Anon.: "Blähtonherstellung durch eine Betonfirma", Brick \& Clay Rec. 138 (1961). Nr. 1, S. 80-81 und 110, 4 Abb.

[65] Versch. Verf.: „Probleme der Herstellung tongebundener Leich blöcke". Brick \& Clay Rec. 138 (1961), Nr. 4, S. 75-78, 117, 118 12C, 122, 124 und 126. (Kurzreferat: Ziegeleitechnisches Jahrbuch 1962, S. 108)

[66] Robinson, C. G.: "Uber die Zuschläge zur Herstellung von Tonleichtblöcken“", Brick \& Clay Rec. 138 (1961), Nr. 5, S. 51 u. 52

[67] Anon.: "Umwandlung einer stillgelegten Ziegelei in einen Blähton-Betrieb", Brick \& Clay Rec. 138 (1961), Nr. 6, S. 66-67 und 73 $5 \mathrm{Abb}$.

[68] Anon.: "Fortschritte in der Herstellung von Tonleichtblöcken", Brick \& "Clay Rec. 139 (1961), Nr. 4, S. 42-45, 4 Abb

[69] Robinson, G. C.: "Die Herstellung von Tonblöcken auf Betonblockmaschinen", (Teil ), Brick \& Clay Rec. 139 (1961), Nr. 6 S. 43-47, 5 Abb., 2 Tab.

[70] Stamboliev, $H_{\text {.: }}$ „Die Herstellung von Hohlleichtzuschlägen durch kontrollierte Vorerhitzung" Journ. Amer Cer Soc 44 (1961). Nr. 12, S. $577-583,11$ Abb., 1 Tab., 13 Ref.

[71] Alviset, M.: „Untersuchung eines blähenden Tones - Leichtzuschläge", L'Industrie Cer. (1961), Nr. 536, S. 459-460, $1 \mathrm{Abb}$. Anon.: "Blähtonherstellung", Brick \& Clay Rec. 140 (1962). Nr. 2, S. $48-50,4 \mathrm{Abb}$

[73] Anon.: Physikalische Eigenschaften tongebundener keramischer Blöcke" Brick \& Clay Rec, 140 (1962) Nr. 3, S. 38-39, 1 Abb. $3 \mathrm{Tab}$.

[74] Robinson, G. C.: „Die Hersteliung von Tonblöcken auf Betonblockmaschinen" (Teil 11). Brick \& Clay Rec. 140 (1962), Nr. 1 , S. $66-89,84$ und 87,7 Abb.. 2 Tab.

[75] Anon.: "Erstes amerikanisches Werk zur Herstellung tongebundener Leichtblöcke", Brick \& Clay Rec. $140(1962)$, Nr. 3, S. $38-40$ und $60,11 \mathrm{Abb}$.

[76] Anon.: „Ein neuer Drehrohrofen zur Blähtonherstellung", Brick \& Clay Rec. 140 (1962), Nr. 5, S. 48 und 49, 3 Abb.

[77] Anon.: "Britisches Werk zur Herstellung von Tonleichtzuschlägen". Anon.: "Britisches Werk zur Herstellung von Tonleichtzuschlägen",
The British Clayworker 70 (1962), Nr. 832, S, 276-279, 8 Abb.

[78] Tscherpak. A. G., und J. P. Kamischansiki (Ubersetzer Dipl.-Ing Böhm): "Ein Typenprojekt für ein Keramsit-Werk", Baustoffe (1962), Böhm): "Ein Typenprojekt für ein Keramsit-Werk"

[79] Kruml, F.: Eigenschaften des Keramsitbetons und seine Verwendung für Bauelemente", Baustoffindustrie (1962), Nr. 8, S. 198 wendung

[80] Iwanow-Djatlow, Swerew, Bitschenkow und Dellos: „KeramsitStahlbeton für eine Spannbetonbrücke", Beton- und StahlbetonStahlbeton für eine Spannt
bau (1962), Nr. 1, S. 24

[81] Anon.: "Leca: Light expanded clay aggregate", Schweizer Tonw. Ind. 65 (1962), Nr. 2, S. 3-6, 6 Abb.

[82] Anon: "Der Tonblock der Zukunft?", Brick \& Clay Rec. 142 (1963), Nr. 2, S. $56-59,11$ Ab

[83] Anon.: "Leichtzuschlagherstellung unter Benutzung einer Strangpresse", Brick \& Clay Rec. 143 (1963), Nr. 5, S. 48, 49 und 67 $3 \mathrm{Abb}$

[84] Anon.: "Eine kritische Betrachtung der Leichtzuschlagherstellung in einer Ziegelei", Brick \& Clay Rec. 143 (1963), Nr. 5. S. 54-56, 6 Abb.

[85] Patrin, P. A.; E. K. Kortschinskij und L. A. Woltschigurskij Versuche mit einem Doppeltrommelofen zum Brennen von Keramsit", Baustoffe (1963), H. 12 [0̄ôj Hunziker AG u. Cie.: ".Leca, ein neuer Baustoff", Schweizer Handelszeitung vom 6 . Juni 1963

[87] Schulz, B.: „Herstellung, Klassierung und Verwendung von Blähton", Beton (1963), H. 8, S. 376-378

(88) Azarov, K. P., und S. I. Michailkovic: "Gasabsonderung beim Aufblähen von Tonen", Novocerkassk (1963), S. 33-43, 6 Abb. 4 Taf. (Kurzreferat Tonind.-Ztg. 89 [1965], Nr. 3/4, S. 86)

[89] Schellmann, W., und H. Fastabend: "Untersuchungen über den Blähprozeß bei Tonen", Die Ziegelindustrie 16 (1963), H. 24, S. 899-905, 3 Abb., 5 Tab., 10 Ref

[90] Anon.: .Ein neuer Begriff für Tonerzeugnisse - jetzt Wirklichkeit", Brick \& Clay Rec. 144 (1964). Nr. 5, S. 36-39, 6 Abb.

[91] Harwell, R. St.: .Die Gewinnmöglichkeiten eines Werkes zur Herstellung von Tonleichtzuschlägen". Brick \& Clay Rec. 145 (1964), Nr. 2, S. $28-31,50,52-53$ und 56, 8 Tab.

[92] Anon.: "SCR Veri-Lite, ein neuer Tonleichtzuschlag“. Amer. Cer. Soc. Bull. 45 (1964). S. 408 u. 409.4 Abb

[93] Böhm, J.: "Ein Typenprojekt für ein Keramsit-Werk", Die Ziegelindustrie 17 (1964), H. 22, S. 829-831, 2 Abb

94] Shirayama, K.: .Die Festigkeit von Konstruktionsleichtbeton und ihre Vorausbestimmung" (Referat Reissmann), Betonsteinzeitung (1964), Nr. 3, S. 144-146

[95] Schulz, B.: "Beitrag zur Technologie des Leichtbetons", Beton Herstellung - Verwendung (1964), Nr. 14, S. 137-142

96] Bertoldi, G.: "Blähton und geblähte Produkte", euro-ceramic (1964), H. 12, S. 272-280, 2 Abb., 83 Ref.

[97] Walz, K. und $G$. Wischers: "Konstruktions-Leichtbeton hoher Festigkeit", Stand der Entwicklung in den USA am Beispiel von Blähtonzuschlag aus dem Drehofen, Beton-Verlag GmbH, Düsseldorf 1954

[98] Walz, K., und G. Wischers: Konstruktions-Leichtbeton hoher Festigkeit", Beton-Jahrbuch 1965

[99] Tauber, E., und D. N. Crook: "Ziegel aus Tonleichtzuschlägen mit Glasbindung", The British "Clayworker 74 (1965), Nr. 873, S. $42-43$

[100] Day, R. B., und P. V. Johnson: ,Verfahren und Apparatur zur Herstellung kleinster Tonzylinder für die Fabrikation von Blähbis $324,2 \mathrm{Abb} .2 \mathrm{Tab}$.

[101] Schtein, J. Sch., J. A. Jakub und W. P. Staroctina: „Keramsitkies für hochfesten Beton", Baustoffe (1965), H. 2, S. 17 [102] Schulz, B.: "Konstruktions-Leichtbeton aus Leca-Blähton", Be-
ton-Herstellung-Verwendung (1965), Nr. 3, S. 93-99, 14 Abb.,

[103] Wesche. K: ., Leichtzuschlagstoffe für den Stahl- und SpannWesche, K.: "Leichtzuschlagstoffe für den Stahl- und

[104] Anon.: "Vorfabrizierte Bauelemente aus Leca“, Industrie-Rund schau (1965), Dez.

[105: Weigler, $H_{\text {. }}$ und $K$. Reissmann: .Untersuchungen an Konstruktionsleichtbeton". Betonsteinzeitung (1965), Nr. 11, S. 615-629

[106] Roesser. K. Erfahrungen mit konstruktivem Leichtbeton in den Vereinigten Staaten von Amerika", Betonsteinzeitung (1965), Nr. 11 S. $63 n-637$

[107] Schulz. B.: Grundlagen für die Herstellung konstruktiver Leichtbetone aus geblähten Zuschlagstoffen", Betonsteinzeitung Leichtbetone aus geblahten Zuschiagstoffen",
(1965), Nr, 11, S. 638-643 und Nr. 12, S. 695-700

[108] Steinicke, K.-H.: Leichtspannbeton und Leichtbeton aus Blähton und Blähschieferton", Bauverlag GmbH. Wiesbaden-Berlin ton und Blahschieferton", Bauverlag GmbH,

[109] Komlos, K: Beitrag zur Untersuchung der Verarbeitbarkeit des Blähton-Betons", Beton- und Stahlbeton (1965). H. 1. S. 15-19, 9 Abb., 10 Ref.

[110] Heufers, H.: "Konstruktionsleichtbeton B 300 aus deutschen geblähten Leichtzuschlagstoffen", Beton-Herstellung - Verwendung $16(1966)$. H. 3. S. 119-124. 10 Abb., 2 Taf., 11 Ref.

[111] Kahl, L..: „US-Patent auf ein Herstellungsverfahren für poröse keramische Erzeugnisse". The British Clayworker 75 (1966) Nr. 894, S. $344-355,2$ Tab

[112] Vieeming, C. R. G.: "Interessante Betriebe und Laboratorien: Hollith", Klei en Keramiek (1966), Nr. 10, S. 303-307, 5 Abb.

[113] Short. A.: "Die Entwicklung des Konstruktionsleichtbetons in Großbritannien", Betonsteinzeitung (1966), Nr. 1, S. 11-17

[114] Rüssemeyer, H.: "Zuschlagstoffe nach Maß". Aufbereitungstechnik 7 (1966), Nr. 4, S. 220-223, 7 Abb

[115] Schwarzkopf, F.: .Blähschiefer und Leichtbetonzuschläge in den USA", Aufbereitungstechnik 7 (1966), Nr. 4, S. 224-228, 3 Abb. 1 Tab.

[116] Bergmann, K.: ..Erfahrungen mit der Hersteliung und Anwendung von Blähtonen"." Die Ziegelindustrie 19 (1966). Nr. 11/12, S. 426 bis $431,15 \mathrm{Abb}$.

[117] Grosskopf. K.: "Blähton ohne Drehrohroten?". Die Ziegelindustrie $19(1966)$. Nr. 11,12, S. 432-436, 3 Abb

[118] Siemssen: E. A. .Das SELAS-Verfahren zur Herstellung von Blähgranulat und seine Verwendung", Die Ziegelindustrie 19 (1966) Nr. 11,12 , S. $437-440$

[119] Böhm, J.: .Ein Keramsitwerk mit Doppeltrommelofen", Die Ziegelindustrie 19 (1966), Nr. 11:12, S. 441-443, $4 \mathrm{Abb}$

[120] Dennert, H. V.: Herstellung von Blähton nach dem ZirkulationsStrömungsverfahren". Die Ziegelindustrie 19 (1966), Nr. 22, S. 827 bis 833,7 Abb., 13 Ref

[121] Schellbach, G.: Neues vom Bauen mit Fertigteilen aus Ziegeln und Blähton" Vortrag anläßlich der 3-Ziegler-Tage 1966 in Essen

[122] Cook, P. B.: Herstellung von Tonleichtzuschlägen nach dem Sin terverfahren" "Claycraft 41 (1967), Nr. 3, S. 74-76 und 79, 2 Abb. 
[123] Thöne, H. H.: „Ein wirtschaftliches Verfahren zur Blähtonerzeugung", Keramische Zeitschrift (1967), H. 11, S. 710-712, $6 \mathrm{Abb}$.

[124] Moeck. M.: „Leichtzuschlagstoffe, Herstellung und Anwendung", Tonind. $-Z \operatorname{tg} 91$ (1967), Nr. 5, S. 175-177, 8 Abb.

[125] Awerbuch, N.: „Ein neues Verfahren zur Herstellung von Schaumtonkörnern", Die Ziegelindustrie 20 (1967), Nr. 14, S. 483-491, $9 \mathrm{Abb}$.

[126] Veit Dennert KG. Schlüsselfeld: „Zirkulations-Strömungsverfahren ,ZS-Verf.' zum Brennen von Blähton", Ziegeleitechnisches Jahrbuch (1967), S. 130-133, 2 Abb.

[127] Anon.: "Leca verdoppelt seine Produktionskapazität", The British Clayworker 77 (1968), Nr. 910, S. 22-29, 11 Abb.

[128] Modde, M. F., und W. G. Lawrence: „Geschäumte Ton-WasserSysteme für die Herstellung leichter Zuschlagstoffe" Bull of the Amer. Cer. Soc. (1968), Nr. 3, S. 264-266, 4 Abb.

[129] Cubaud, J. C., und M. Murat: Industrielle Herstellung von expandiertem Ton", Silikates Industriels (1968), Nr. 5, S. 145-152, 4 Abb., 1 Tab.

[130] Steindl, A.: Geblähte keramische Zuschlagstoffe im heutigen Baugeschehen", Ziegeleitechnisches Jahrbuch (1968), S. 361-404 $30 \mathrm{Abb}, 1 \mathrm{Tab}, 13$ Ref.

[131] MIAG, Mühlenbau und Industrie GmbH, Braunschweig: Brenneinrichtung für Blähton", Ziegeleitechnisches Jahrbuch" (1968), $\mathrm{S} .127-131,3 \mathrm{Abb}$

[132] MIAG, Mühlenbau und Industrie GmbH, Braunschweig: Neues Blähtonwerk in Betrieb genommen", Die Ziegelindustrie 21 " (1968). Nr. 20 , S. 472, Abb.

[133] Schellmann, W.: "Das Blähvermögen von Tonen und seine Ursachen", Sprechsaal 101 (1968), Nr. 17/18, S. 721-730, 3 Abb.

[134] Routschka, G., und Ch. Buttgereit: "Beitrag zum Blähen von Tonen und Schamotteerzeugnissen der Feuerfestindustrie, insbesondere der blähenden Pfannensteine", Sprechsaal 101 (1968) Nr. 22, S. 994-1000, 4 Abb., 3 Tab., 23 Re

[135] Möller, F.: "Untersuchungen an Tonen, Tonschiefern und Schlacken auf ihre Eigenschaften zur Herstellung von Blähtonprodukten", Tonind.-Ztg. 92 (1968), Nr. 12, S. 498-501, 7 Abb. 4 Ref

[136] Bender, W.: „Aufbereitung und Formgebung bei der Blähton herstellung", Die Ziegelindustrie 21 (1968), S. 196-199, $10 \mathrm{Abb}$
[137] Fa. Händle, Mühlacker/Württ.: „Blähton“, Ziegeleitechnisches Jahrbuch (1968) Anzeige

[138] Körner, W.: "Erzeugung von Leichtbeton unter Verwendung geblähter Zuschlagstoffe", Betonsteinzeitung (1969), H. 6, S. 365 bis $369,1 \mathrm{Abb}$

[139] Fa. Fr. Kettenbauer, Murg/Baden: ,Neue Erfahrungen in der Herstellung von Blänton", Zement-Kalk-Gips (1969), Nr. 5, S. 247 bis 248,2 Abb.

[140] Pfefferkorn, W., "Bemessung von Bauwerken aus Stahlleichtbeton", Betonsteinzeitung (1969). H. 6, S. 359-364, 10 Ref.

[141] Hoffmann, H.: "Das Blähvermögen des Unterloquitzer Dachschiefers", Silikattechnik 20 (1969), H. 11, S. 380-383, 8 Abb. 4 Ref.

[142I Häusser. A.: „DIE ZIEGELINDUSTRIE - Baustoffe gestern, heute und morgen", Die Ziegelindustrie 22 (1969), Nr. 9/10, S. 214-218 Nr. $11 / 12$, S. $268-272,1$ Abb.; Nr. $15 / 16$, S. $346-348$; Nr. 19 S. $439-442$ und Nr. 20, S. $466-469$

[143] Krause, H. J.: Betrachtungen, Untersuchungen und Entwicklungen bei der Blähtonherstellung in Form von Granulaten und keramischer Bindung", Die Ziegelindustrie 22 (1969), Nr. 11/12, S. $260 \cdots 264,6 \mathrm{Abb}$. und Keram. Zeitschrift (1968), H. 4

[144] Kettenbauer, F.: "Keramische Bindung", Die Ziegelindustrie 22 (1969), Nr. 20, S. " 481

[145] Rieter-Werke, Konstanz: "Möglichkeiten zur Tonaufbereitung und Pelletisierung in der Blähtonherstellung ". Die Ziegelindustrie 22 (1969), Nr. 23/24. S. 582-583, 3 Abb.

[146] Mozer AG., Göppingen: "Drehrohröfen", Ziegeleitechnisches Jahrbuch (1969), S. 516 (Anzeige)

[147] Tacken, J.: "Blähtonprodukte aus glaukonitreichen Tonen", Tonind-Ztg. 93 (1969), Nr. 9, S. 314-318, 2 Abb., 3 Taf., 6 Ref.

[148] Eirich, G.: "Aufbereitungsanlage", Die Ziegelindustrie 22 (1969) Nr. 11/12, S. A 24 (Anzeige)

[149] Giesche's Erben, G. v. "Leca“, Ziegeleitechnisches Jahrbuch (1969), S. 515 (Anzeige)

[150] Fr. Krupp GmbH, Rheinhausen: Krupp-Blähtonanlage“, Ziegeleitechnisches Jahrbuch (1970), S. 98-99

[151] Kromer, H.: "Mineralogische und erhitzungsmikroskopische Untersuchung an Blähtonen", Vortrag anläßlich der 5. Tagung über das Gebiet feiner Teilchen am 2. 4. 1970 im Haus der Technik in Essen

[152] Fr. Krupp GmbH, Rheinhausen: „Blähtontag" anläßlich der Hanncver-Messe am 28. April 1970

\section{ediffeios de viviendas prefabricadas con elementos de grandes dimmensiones}

\section{Bohdan Lewicki}

El libro del profesor B. Lewicki puede considerarse como uno de los más completos referentes a la prefabricación e industrialización de viviendas a base de de grandes paneles.

El autor, eminente especialista reconocido internacionalmente, es Jefe del Departamento de Hormigón Armado en el Instituto para Técnica de la Construcción y Secretario de la Comisión Civil de la Academia de Ciencias de Varsovia. Conoce a fondo los problemas teoricos y prácticos de las construcciones prefabricadas, como investigador $\mathrm{y}$, al mismo tiempo, como activo participante en la reconstrucción de su pais, campo de experiencias a escala real de una amplitud no superada en otro pais.

La obra en cuestión recoge las vertientes técnica y científica de los complejos problemas inherentes a las construcciones industriales, en especial los que se refieren a métodos de cálculo de arriostramiento, de forjados y muros, así como los de origen higrotérmico, acústico, resistencia al fuego, etc.

La presente edición se halla enriquecida con numerosas ilustraciones que proporcionan detalles de soluciones, tablas numéricas, diagramas y ábacos.

La versión que ofrecemos consiste en la traducción y adaptación de la obra a los parámetros, terminología y condiciones técnológicas españolas, y ha sido realizado por el doctor arquitecto Fernando Aguirre de Yraola, Jefe de la Sección de Industrialización del I.E.T.c.c., como producto de la colaboración de esta Sección, a lo largo de varios años, con el profesor Lewicki. Esta colaboración ha permitido incluir en la obra las recomendaciones y estudios seguidos en nuestro pais sobre disciplinas dimensionales y coordinación modular, así como sustituir algunos ejemplos prácticos de cálculo de edificaciones polacas por otras similares correspondientes a los estudios de soluciones especificamente espaniolas.

Encuadernado en tela, $24,5 \times 17,5 \mathrm{~cm}, 615$ páginas.

Precios: España, 1.000 ptas.; extranjero, \$20. 